\title{
Main Group Element Isophlorin Complexes Revisited: The Question of a Subvalent Central Atom
}

\author{
Jeanet Conradie, ${ }^{\mathrm{a}, \mathrm{b}}$ Penelope J. Brothers ${ }^{\mathrm{a}, \mathrm{c}}$ and Abhik Ghosh * a
}

${ }^{a}$ Department of Chemistry, UiT - The Arctic University of Norway, 9037 Troms $\varnothing$, Norway;

E-mail: abhik.ghosh@uit.no (AG)

${ }^{\mathrm{b}}$ Department of Chemistry, University of the Free State, 9300 Bloemfontein, Republic of South Africa

${ }^{c}$ School of Chemical Sciences, The University of Auckland, Private Bag 92019, Auckland, New Zealand.

\begin{abstract}
A careful DFT reexamination of the geometric and electronic structures of reduced main-group porphyrin complexes $\mathrm{E}(\mathrm{Por}) \mathrm{L}_{2}(\mathrm{M}=\mathrm{Si}$ or $\mathrm{Ge}, \mathrm{L}=$ pyridine or thf $), \mathrm{B}_{2}(\mathrm{Por})$, and $\mathrm{C}_{2}$ (Por) has confimed these as pure isophlorin complexes with normal-valent coordinated central atoms. Only, axially unligated $\mathrm{Ge}$ (Por) and the dications $\left[\mathrm{B}_{2}(\mathrm{Por})\right]^{2+}$ and $\left[\mathrm{C}_{2}(\mathrm{Por})\right]^{2+}$ feature aromatic porphyrin ligands. The calculations faithfully reproduce the strong bond length alternation along the outer rim of the macrocycle in the reduced complexes, consistent with antiaromatic character, as well as much stronger ruffling in the reduced Group 14 complexes relative to nonreduced complexes such as $\mathrm{M}(\mathrm{Por}) \mathrm{X}_{2}(\mathrm{M}=\mathrm{Si}$ or $\mathrm{Ge}, \mathrm{X}=\mathrm{F}$ or $\mathrm{Cl})$. The latter is thought to reflect the lower barrier to nonplanar deformation for the antiaromatic systems. In addition, unlike $\mathrm{B}_{2}$ (Por) and its dication, which are planar, $\mathrm{C}_{2}$ (Por) and its dication are predicted to be strongly ruffled, reflecting the smaller size of the center $\mathrm{C}_{2}$ unit. The calculations also predict characteristically low ionization potentials and singlet-triplet gaps for the antiaromatic complexes. A brief exploratory study of the as yet unknown Group 15 complexes $\mathrm{M}(\mathrm{TPP})(\mathrm{Ph})(\mathrm{py})$, where $\mathrm{M}=\mathrm{P}$ and $\mathrm{As}$, also indicated an antiaromatic isophlorin macrocycle coordinated to a pentavalent Group 15 center.
\end{abstract}


Introduction. Classical main group chemistry (except for period 2) typically exhibits stable group oxidation states equivalent to the group number (e.g., +3 for Group $13,+5$ for Group 15, etc.). Typical formulations observed for porphyrin complexes with elements (E) from Groups 1, 2 and 13-15 are $\mathrm{E}_{2}^{\mathrm{I}}$ (Por), $\mathrm{E}^{\mathrm{II}}$ (Por), $\mathrm{E}^{\mathrm{III}}$ (Por)X, $\mathrm{E}^{\mathrm{IV}}\left(\right.$ Por) $\mathrm{X}_{2}$, and $\left[\mathrm{M}^{\mathrm{V}}(\text { Por }) \mathrm{X}_{2}\right]^{+}$, respectively. For sixth-period p-block elements, oxidation states two units lower than the group oxidation states are also observed, as in $\mathrm{Tl}_{2}^{\mathrm{I}}$ (Por), $\mathrm{Pb}^{\mathrm{II}}$ (Por), and $\mathrm{Bi}^{\mathrm{III}}$ (Por)X for Groups 13-15). ${ }^{1,2}$ Against this backdrop, Vaid and coworkers have reported a number of reduced Group 14 porphyrin derivatives whose molecular formulas superficially correspond to $\mathrm{M}^{\mathrm{II}}\left(\right.$ Por $\left.^{2-}\right)$ or $\mathrm{M}^{\mathrm{II}}\left(\operatorname{Por}^{2-}\right) \mathrm{L}_{2}$, where $\mathrm{M}=\mathrm{Si}$ or Ge (but not $\mathrm{Sn}$ ) and $\mathrm{L}$ is a neutral ligand such as pyridine or thf (Scheme 1). ${ }^{3,4,5,6}$ Remarkably, the two complexes Ge(TPP) and Ge(TPP)(py) 2 (TPP = meso-tetraphenylporphyrin), both crystallographically characterized, were found to exhibit dramatically different behavior relative to each other. ${ }^{4}$ Thus, Ge(TPP) is aromatic and its structural and spectroscopic features are consistent with a $\mathrm{Ge}^{\mathrm{II}}\left(\mathrm{Por}^{2-}\right)$ formulation, whereas $\mathrm{Ge}(\mathrm{TPP})(\mathrm{py})_{2}$ exhibits strong bond length alternation along the outer rim of the porphyrin, with ${ }^{1} \mathrm{H}$ NMR studies and NICS calculations indicating an antiaromatic macrocycle. ${ }^{7,8,9}$ Additional analogues of the latter compound have also been reported and include $\mathrm{Si}(\mathrm{TPP}) \mathrm{L}_{2}$ $\left(\mathrm{L}=\right.$ thf, py), $\mathrm{Si}(\mathrm{Pc})(\mathrm{py})_{2}$, and $\mathrm{Ge}(\mathrm{Pc})(\mathrm{py})_{2}(\mathrm{Pc}=\text { phthalocyanine })^{3,5,6}$ The antiaromatic character of these complexes was interpreted in terms of a tetraanionic, two-electron-reduced porphyrin (or Pc) ligand, a so-called isophlorin coordinated to an M(IV) center, i.e., $\mathrm{M}^{\mathrm{IV}}\left(\mathrm{Por}^{4-}\right) \mathrm{L}_{2}$.

Porphyrin derivatives with coordinated $\mathrm{B}_{2}$ and $\mathrm{C}_{2}$ units provide additional examples of reduced p-block element porphyrins. The $\mathrm{B}_{2}$ porphyrins have been characterized in two different oxidation states. The diboranyl porphyrins $(\mathrm{XBBX})(\mathrm{TPP})\left(\mathrm{X}=\mathrm{F}, \mathrm{Cl},{ }^{\mathrm{n}} \mathrm{Bu}\right)$ and $\left[\left(\mathrm{B}_{2}\right)(\mathrm{TPP})\right]^{2+}$, which contain a formal B-B single bonded $\left[\mathrm{B}_{2}^{\mathrm{II}}\right]^{4+}$ unit, exhibit spectroscopic behavior typical of an aromatic macrocycle and are readily formulated as $\left[\left(\mathrm{B}_{2}{ }_{2}\right)\left(\mathrm{Por}^{2-}\right)\right]^{2+} .10,11$ The reduced, neutral complex $\left(\mathrm{B}_{2}\right)(\mathrm{TPP})$, on the other hand, appears to feature a formal $\left[\mathrm{B}_{2}{ }_{2}\right]^{2+}$ group with a $\mathrm{B}=\mathrm{B}$ double bond. On closer inspection, this complex was also found to be an isophlorin derivative with a B-B single bond and an antiaromatic $\left(\mathrm{B}_{2}{ }_{2}\right)\left(\right.$ Por $\left.^{4-}\right)$ electronic description (Scheme 1) ${ }^{11}$ An equivalent set of $\mathrm{C}_{2}$ porphyrins containing $\mathrm{C}=\mathrm{C}$ units has also been reported $-\left[\left(\mathrm{C}_{2}\right)(\mathrm{TPP})\right]^{2+}$, which is aromatic, and $\left(\mathrm{C}_{2}\right)(\mathrm{TPP})$, the reduced, antiaromatic isophlorin form. ${ }^{12,13}$

Although quantum chemical calculations (geometry optimizations) accompanied several of the experimental reports, ${ }^{3,4,11}$ no comprehensive theoretical study has addressed the 
field as a whole. Presented herein is such a study, where the key question has been whether the central atoms in these complexes exhibit any degree of subvalent or low-oxidation-state character. ${ }^{14,15,16}$ We have also briefly examined reduced group 15 porphyrins involving phosphorus and arsenic, ${ }^{17,18,19}$ which as of today remain poorly explored.
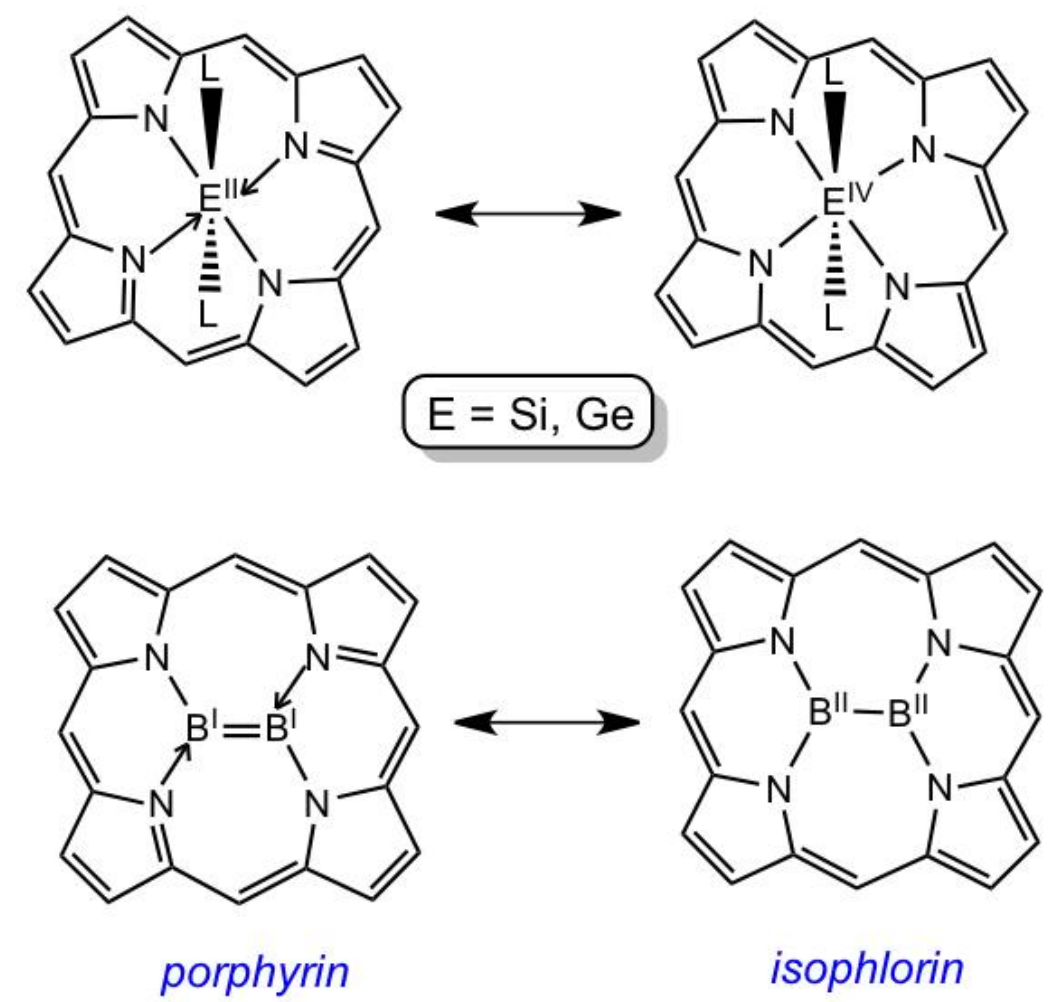

Scheme 1. Limiting-case descriptions for reduced Group $14(\mathrm{M}=\mathrm{Si}, \mathrm{Ge})$ and diboron porphyrins.

\section{Results and discussion}

Three different density functional theory (DFT) methods - BP86, ${ }^{20,21}$ OLYP, $, 22,23$ and B3LYP ${ }^{24}-\mathrm{D} 3^{25}$ - were used to examine a selection of reduced silicon, germanium, $\mathrm{B}_{2}, \mathrm{C}_{2}$, phorphorus, and arsenic porphyrin derivatives. Table 1 presents key B3LYP-D3 results, including selected optimized geometry parameters for these complexes and adiabatic ionization potentials and singlet-triplet gaps; the other two functionals yielded very similar results in essentially all cases. Selected structural data from experimental X-ray analyses are also included in Table 1.

(a) Reduced silicon and germanium porphyrins. The optimized geometries of the reduced six-coordinate complexes $\mathrm{E}(\mathrm{TPP}) \mathrm{L}_{2}$, where $\mathrm{M}=\mathrm{Si}$ or $\mathrm{Ge}, \mathrm{L}=$ pyridine (py) or tetrahydrofuran (thf), and TPP = tetraphenylporphyrin, are in excellent agreement with the X- 
ray structures of $\mathrm{Si}(\mathrm{TPP})(\mathrm{thf})_{2}\left(\mathrm{CSD}\right.$ : QATVIR $\left.{ }^{3}\right)$ and $\mathrm{Ge}(\mathrm{TPP})(\mathrm{py})_{2}\left(\mathrm{LIHYAD}^{4}\right)($ Figure 1$)$. These structures exhibit pronounced bond length alternation along the outer $\mathrm{C}_{20}$ perimeter of the macrocycle, as expected for isophlorin derivatives. Notably, no bond length alternation is associated with the $\mathrm{N}-\mathrm{C}_{\alpha}$ bonds in these compounds. Another interesting aspect of these structures is that, both experimentally and theoretically, the reduced six-coordinate complexes are significantly more ruffled than their aromatic dihalogeno analogues $\mathrm{E}(\mathrm{TPP}) \mathrm{X}_{2}$ (see the ruffling dihedrals $\chi$ listed in Table 1). ${ }^{26,27}$ A plausible explanation for this difference is that there is less of an energy cost associated with nonplanar deformation of an antiaromatic isophlorin relative to an aromatic porphyrin..$^{28,29,30}$ Peripheral bond length alternation and ruffling together result in an overall lower molecular symmetry, $D_{2}$, for the reduced six-coordinate complexes $\mathrm{E}(\mathrm{TPP}) \mathrm{L}_{2}$, which may be compared with $D_{2 \mathrm{~d}}$ for $\mathrm{Si}(\mathrm{TPP}) \mathrm{F}_{2}$ $\left(\mathrm{RITFOP}^{26}\right)$ and approximately $D_{4 \mathrm{~h}}$ for $\mathrm{Ge}(\mathrm{TPP}) \mathrm{Cl}_{2}\left(\mathrm{NIPKEC}^{27}\right)$. For the four-coordinate complex Ge(TPP), the calculations also led to a delocalized structure, consistent with an aromatic $\mathrm{Ge}^{\mathrm{II}}\left(\right.$ Por $\left.^{2-}\right)$ formulation and in excellent agreement with the crystal structure $\left(\operatorname{LIJVAC}^{4}\right)$. The calculations, however, failed to converge for a closed-shell singlet state of the analogous four-coordinate $\mathrm{Si}$ complex $\mathrm{Si}(\mathrm{TPP})$. Given that $\mathrm{Sn}(\mathrm{II})$ porphyrins are stable, the results clearly indicate that the stability of the four-coordinate E(II) state follows the expected order $\mathrm{Si}^{\mathrm{II}}<\mathrm{Ge}^{\mathrm{II}}<\mathrm{Sn}^{\mathrm{II}}$, as indeed pointed out by Vaid et al. ${ }^{4}$
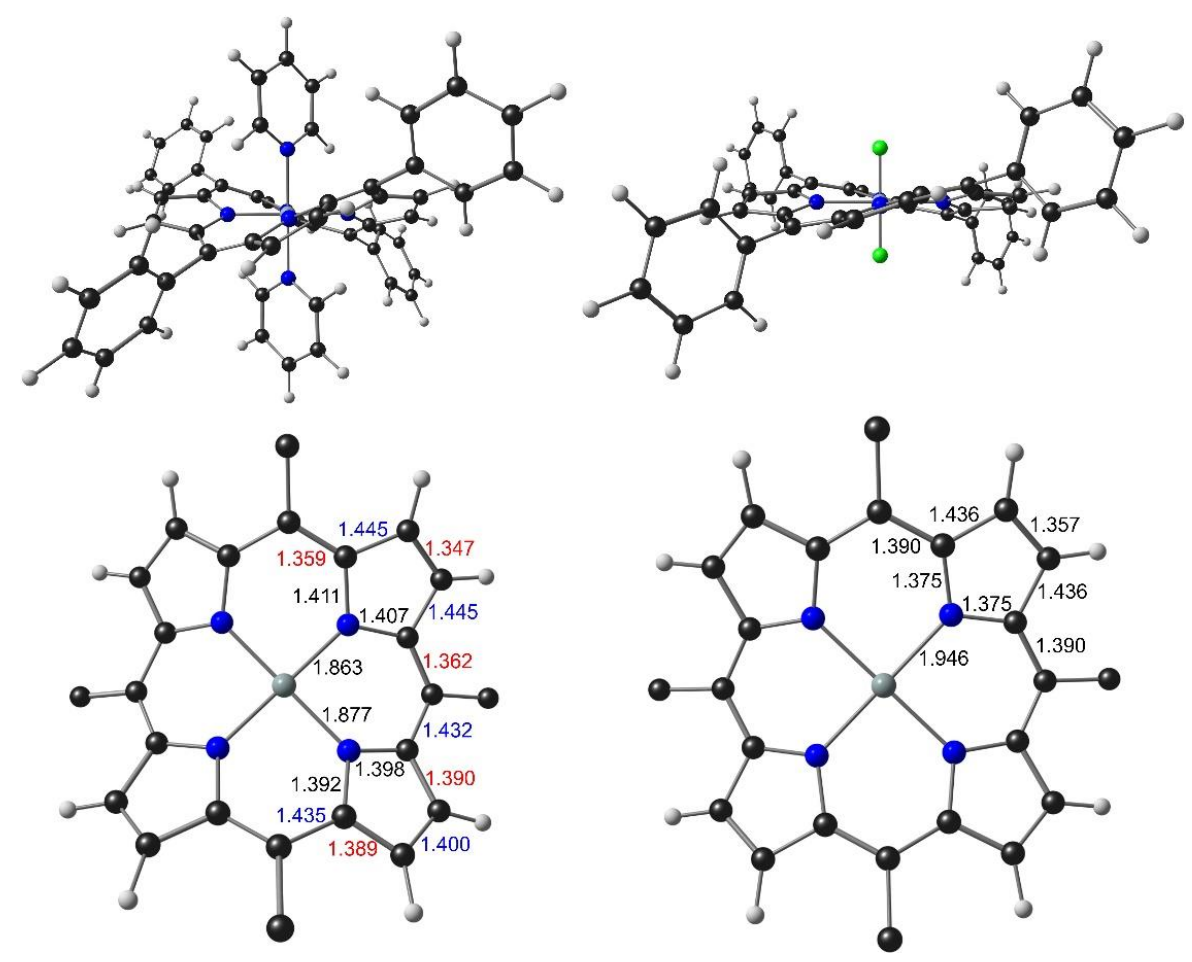

Figure 1. Highlights of the B3LYP-D3/STO-TZ2P optimized geometries ( $\mathrm{A}$ ) for $\mathrm{Si}(\mathrm{TPP})(\mathrm{py})_{2}($ left $)$ and $\mathrm{Si}(\mathrm{TPP}) \mathrm{F}_{2}$ (right). 
(b) Diboron and dicarbon porphyrins. Geometry optimization of unsubstituted $\mathrm{B}_{2}$ (Por) and $\mathrm{B}_{2}$ (TPP) led to $C_{2 \mathrm{~h}}$ final geometries with planar macrocyclic cores and strong bond length alternation along the $\mathrm{C}_{20}$ periphery, consistent with an $\mathrm{E}_{2}{ }^{\mathrm{II}}\left(\mathrm{Por}^{4-}\right)$ isophlorin formulation (Figure 2). In an attempt to locate a diborene-porphyrin state containing a $\mathrm{B}^{\mathrm{I}}=\mathrm{B}^{\mathrm{I}}$ fragment ${ }^{11}$ we optimized $\mathrm{B}_{2}$ (Por) with a $D_{2 \mathrm{~h}}$ symmetry constraint. However, the resulting structure, at an energy of $0.19 \mathrm{eV}$ at the B3LYP-D3/STO-TZ2P level (and at $0.06 \mathrm{eV}$ with OLYP) relative to the $C_{2 \mathrm{~h}}$ minimum, corresponded to the transition state for bond-shift selfisomerization of the molecule. ${ }^{31,32,33}$ Indeed, the B-B distance in the $D_{2 \mathrm{~h}}$ structure turned out to be slightly longer than that in the $C_{2 \mathrm{~h}}$ minimum, strongly arguing against a diborene description (Figure 2a,b). As a last resort, we searched for a diborene-porphyrin local minimum by carrying out linear-transit $C_{2 \mathrm{~h}}$ and $D_{2 \mathrm{~h}}$ calculations as a function of the B-B distance, but again to no avail. The potential energy curve obtained indicated a single minimum corresponding to the bond-alternating $C_{2 \mathrm{~h}}$ geometry (Figure 3). Unsurprisingly, geometry optimization of dicationic species $\left[\mathrm{B}_{2} \text { (Por) }\right]^{2+}$ and $\left[\mathrm{B}_{2}(\mathrm{TPP})\right]^{2+}$ yielded delocalized macrocyclic cores with peripheral bond length alternation, signifying aromatic, porphyrin states (Figure 4).

(a)

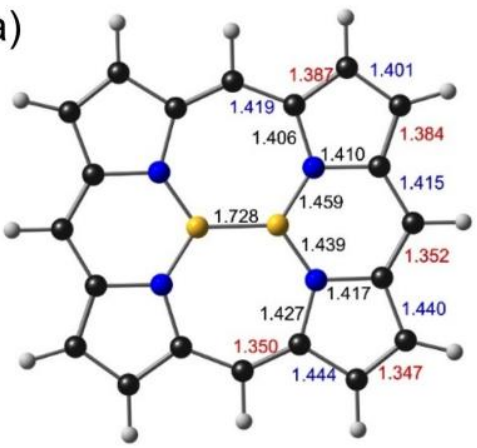

(b)

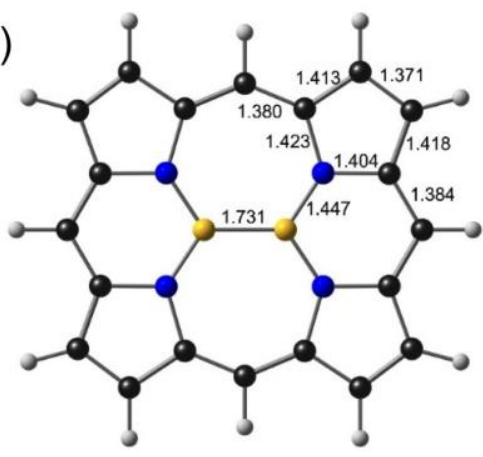

(c)

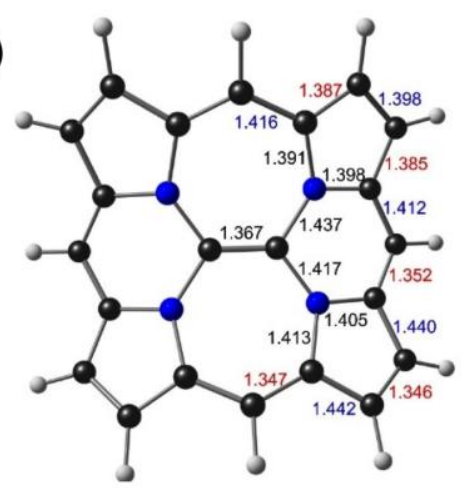


Figure 2. Highlights of the B3LYP-D3/STO-TZ2P optimized geometries for (a) the $C_{2 \mathrm{~h}}$ global minimum and (b) the $D_{2 \mathrm{~h}}$ transition state structure of $\mathrm{B}_{2}(\mathrm{Por})$; and (c) the $C_{2}$ optimized structure of $\mathrm{C}_{2}$ (Por).

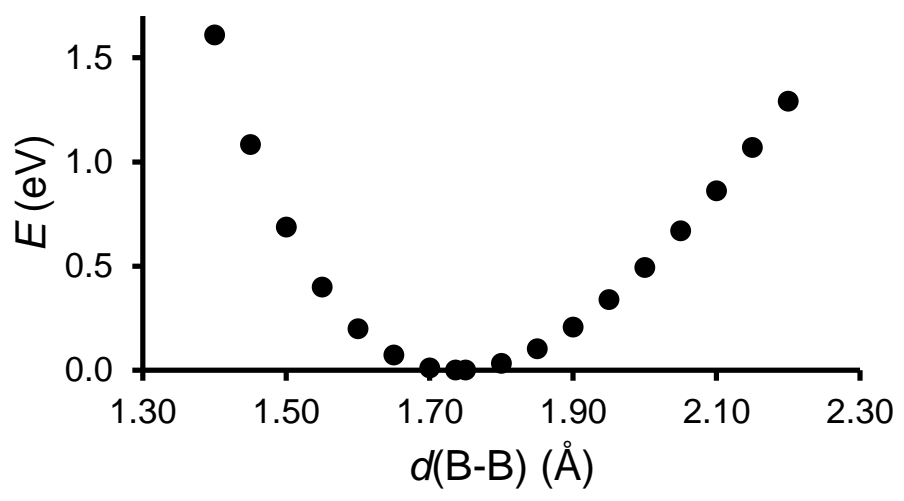

Figure 3. Potential energy scan for $\mathrm{B}_{2}$ (Por) as a function of the B-B distance.
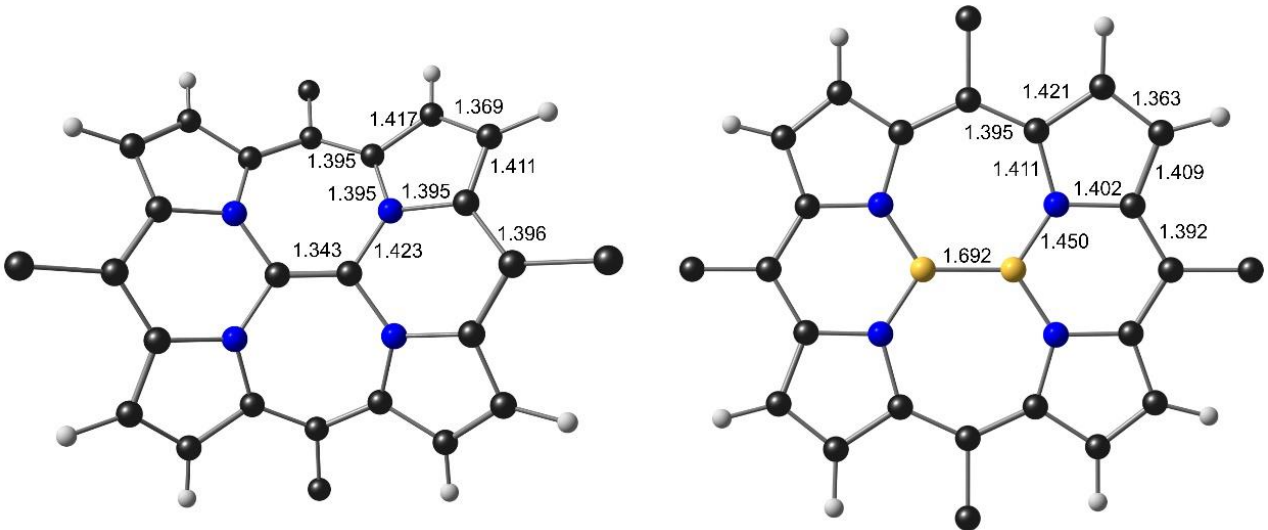

Figure 4. Highlights of the B3LYP-D3/STO-TZ2P optimized structures of $\left[\mathrm{C}_{2}(\mathrm{TPP})\right]^{2+}($ left, $C_{2}$, ruffled) and $\left[\mathrm{B}_{2}(\mathrm{TPP})\right]^{2+}$ (right, $C_{2 \mathrm{~h}}$, planar).

In many ways, geometry optimization of dicarbon porphyrin derivatives led to results analogous to those obtained for the diboron systems (Figures $2 \mathrm{c}$ and 4 ). Thus, bondalternating structures were obtained for neutral, unsubstituted $\mathrm{C}_{2}$ (Por) and for $\mathrm{C}_{2}$ (TPP), while delocalized structures were obtained for $\left[\mathrm{C}_{2}(\text { Por })\right]^{2+}$ and $\left[\mathrm{C}_{2}(\mathrm{TPP})\right]^{2+}$. In other words, the neutral species are best regarded as isophlorins and the dications as porphyrins. The optimized geometries of the diboron and dicarbon complexes do exhibit one key difference, however: whereas the diboron systems, as described above, are essentially planar, the dicarbon systems are strongly ruffled. This difference, which holds for both the neutral antiaromatic and the dicationic aromatic states, is reasonably ascribed to the much shorter, central carbon-carbon bonds $(\sim 1.3 \AA$ ) in the dicarbon systems relative to the boron-boron bonds in the diboron systems $(\sim 1.7 \AA$; see Table 1 and Figures 2 and 4 for details $)$. As is 
well-known, a smaller coordinated "element", in these cases a two-atom ellipsoid, results in an increased propensity for ruffling. ${ }^{29}$

(c) Electronic-structural considerations. The change in electron distribution from $\mathrm{E}^{\mathrm{II}}($ Por $)$ to $\mathrm{E}^{\mathrm{IV}}\left(\mathrm{TPP}^{4-}\right) \mathrm{L}_{2}(\mathrm{E}=\mathrm{Si}, \mathrm{Ge})$ requires the migration of two electrons from an $\mathrm{E}\left(\mathrm{p}_{\mathrm{z}}\right)$ orbital to one of porphyrin $e_{g}$ LUMOs. Given that the $p_{z}$ and the $e_{g}$ MOs are orthogonal by symmetry, electron migration between them can only happen in an all-or-none manner. NBO analyses also did not evince any indication of a lone pair on the central element in the sixcoordinate $\mathrm{E}(\mathrm{TPP}) \mathrm{L}_{2}$ complexes. Thus, both qualitative symmetry considerations and quantitative calculations categorically ruled out any trace of $\mathrm{E}(\mathrm{II})$ character in these sixcoordinate reduced complexes, thus confirming their status as pure isophlorin complexes. For $\mathrm{B}_{2}$ (Por) $\left(C_{2 \mathrm{~h}}\right)$, the $\pi$-symmetry occupied MOs were found to exhibit varying degrees of B-B bonding and antibonding character (Figure 5). NBO analysis, however, confirmed only a single B-B $\sigma$ bond for the complex, again as expected for a pure isophlorin derivative. In other words, of the various complexes considered so far, only Ge(TPP) qualifies as a genuine low-oxidation-state p-block element complex of a true porphyrin.

Our calculations also indicated low adiabatic ionization potentials $\lesssim 5.25 \mathrm{eV}$ and low adiabatic singlet-triplet gaps of only $0.1-0.25 \mathrm{eV}$ for the reduced antiaromatic complexes, relative to the true, aromatic porphyrin derivatives. By comparison, typical closed-shell porphyrins exhibit gas-phase ionization potentials $>6.0 \mathrm{eV}^{34,35,36}$ and singlet-triplet gaps around $2.0 \mathrm{eV}$.

A detailed analysis of magnetically induced currents, such as we $\mathrm{e}^{37,38,39}$ and others ${ }^{40}$ have reported for other porphyrinoid systems, would be of unusual interest for the present antiaromatic isophlorin derivatives. However, the small HOMO-LUMO gaps of these complexes introduces significant doubt into the validity of the currents calculated at the DFT level. Accordingly, as in the case of our recent study of norcorrole, we have chosen to defer a discussion of magnetically induced currents until such time as ab initio multiconfigurational (MCSCF) calculations prove feasible for the present systems. ${ }^{41}$ 


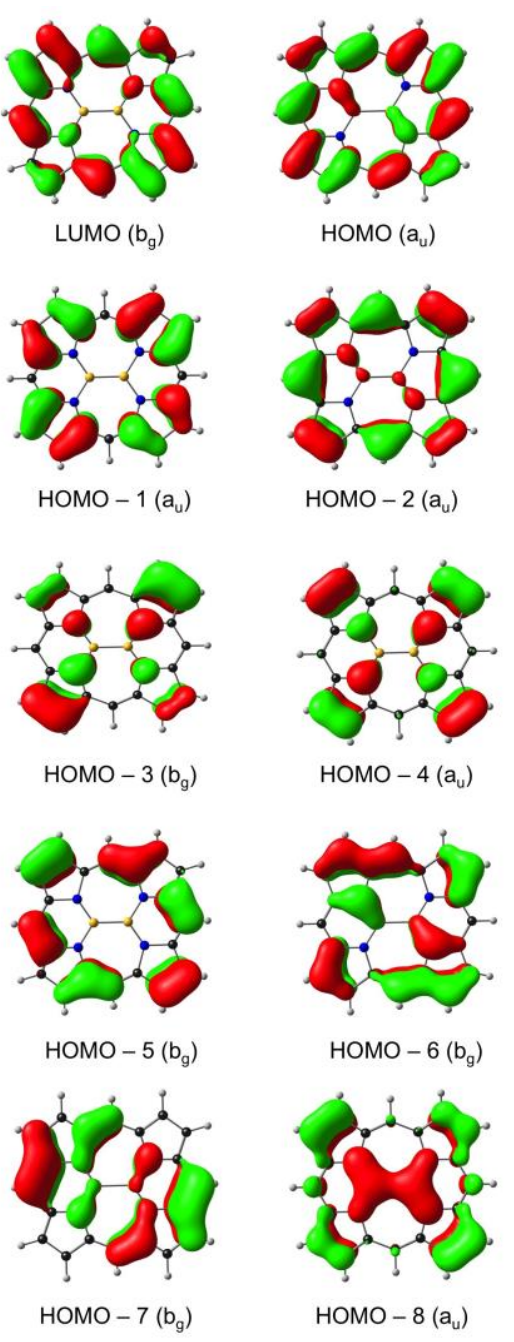

Figure 5. Frontier MOs of $\mathrm{B}_{2}$ (Por) $\left(C_{2 \mathrm{~h}}\right)$.

(d) Reduced phosphorus and arsenic porphyrins. While $\mathrm{P}(\mathrm{V})$ and $\mathrm{As}(\mathrm{V})$

porphyrins are well-established, the analogous E(III) complexes are essentially unknown. ${ }^{18,19}$ Our DFT calculations on the five-coordinate complexes E(TPP)(X) and the six-coordinate complexes $\mathrm{E}(\mathrm{TPP})(\mathrm{X})(\mathrm{py})(\mathrm{E}=\mathrm{P}, \mathrm{As} ; \mathrm{X}=\mathrm{Cl}, \mathrm{Ph})$ yielded somewhat confusing results. Thus, while B3LYP-D3 calculations predicted triplet ground states for certain of the five-coordinate complexes including $\mathrm{P}(\mathrm{TPP}) \mathrm{Cl}$ and $\mathrm{As}(\mathrm{TPP}) \mathrm{Ph}$, they predicted the expected, singlet antiaromatic states for $\mathrm{P}(\mathrm{TPP}) \mathrm{Ph}$ and for all four six-coordinate $\mathrm{E}(\mathrm{TPP})(\mathrm{X})(\mathrm{py})$ species examined, consistent with an $\mathrm{E}^{\mathrm{V}}$-isophlorin description (Table 1). The calculations also predicted strongly ruffled geometries for these species, as for their Si and Ge congeners. The potential isolation of these reduced Group 15 complexes remains an intriguing goal for this field. 


\section{Conclusion}

A careful DFT reexamination of reduced main-group porphyrins has confirmed that the great majority of them are pure isophlorin complexes with no trace of low-oxidation-state or subvalent character. Thus, reduced six-coordinate complexes of the type $\mathrm{E}(\mathrm{Por}) \mathrm{L}_{2}$, where $\mathrm{M}$ $=\mathrm{Si}$ or $\mathrm{Ge}$, and $\mathrm{L}$ is a neutral ligand, are all to be regarded as $\mathrm{E}^{\mathrm{IV}}\left(\operatorname{Por}^{4-}\right) \mathrm{L}_{2}$, with a normalvalent main-group center. Likewise, $\mathrm{B}_{2}($ Por $)$ should be viewed as $\left(\mathrm{B}^{\mathrm{II}}\right)_{2}\left(\mathrm{Por}^{4-}\right)$, i.e., as a diboranyl-isophlorin with normal trivalent boron atoms linked by a single bond as opposed to a diborenyl-porphyrin. ${ }^{14}$ A significant structural insight from this work is that antiaromatic isophlorin species are more prone to ruffling than related aromatic porphyrin species. Also, unlike $\mathrm{B}_{2}$ (Por) and its dication, which are planar, $\mathrm{C}_{2}$ (Por) and its dication are predicted to be strongly ruffled, reflecting the smaller size of the center $\mathrm{C}_{2}$ unit. Finally, a brief exploratory study of the as yet unknown complexes $\mathrm{M}(\mathrm{TPP})(\mathrm{Ph})(\mathrm{py})$, where $\mathrm{M}=\mathrm{P}$ and As, also indicated an antiaromatic isophlorin macrocycle coordinated to a pentavalent Group 15 center. 
Table 1. Selected B3LYP-D3/STO-TZP results: bond distances $(\AA),{ }^{a}$ ruffling dihedrals $\left(\chi,{ }^{\circ}\right)$, adiabatic singlet-triplet gaps $\left(E_{\mathrm{ST}}, \mathrm{eV}\right)$ and ionization potentials (IP, eV); distances in italics are from experimental X-ray structures.

\begin{tabular}{|c|c|c|c|c|c|c|c|c|c|c|c|c|c|}
\hline & $\mathrm{M}-\mathrm{N}$ & M-L ${ }_{a x}$ & $\mathrm{~N}-\mathrm{C}_{\alpha}$ & $\left(\mathrm{C}_{\beta}-\mathrm{C}_{\beta}\right)_{1}$ & $\left(\mathrm{C}_{\beta}-\mathrm{C}_{\beta}\right)_{\mathrm{S}}$ & $\left(\mathrm{C}_{\alpha}-\mathrm{C}_{\beta}\right)_{1}$ & $\left(\mathrm{C}_{\alpha}-\mathrm{C}_{\beta}\right)_{\mathrm{s}}$ & $\left(\mathrm{C}_{\alpha}-\mathrm{C}_{\text {meso }}\right)_{1}$ & $\left(\mathrm{C}_{\alpha}-\mathrm{C}_{\text {meso }}\right)_{\mathrm{s}}$ & $\chi$ & $E_{\mathrm{ST}}$ & IP & CSD code \\
\hline $\mathrm{Si}(\mathrm{TPP})(\mathrm{py})_{2}$ & 1.870 & 2.022 & 1.402 & 1.400 & 1.347 & 1.445 & 1.389 & 1.433 & 1.361 & 54.0 & 0.22 & 4.24 & \\
\hline \multirow[t]{2}{*}{$\mathrm{Si}(\mathrm{TPP})(\text { thf })_{2}$} & 1.862 & 1.924 & 1.403 & 1.401 & 1.349 & 1.446 & 1.392 & 1.433 & 1.361 & 55.7 & 0.24 & 4.34 & \\
\hline & 1.844 & 1.891 & 1.400 & 1.399 & 1.346 & 1.442 & 1.386 & 1.439 & 1.369 & 61.1 & & & QATVIR $^{3}$ \\
\hline \multirow[t]{2}{*}{$\mathrm{Si}(\mathrm{TPP}) \mathrm{F}_{2}$} & 1.946 & 1.671 & 1.375 & 1.357 & - & 1.436 & - & 1.390 & - & 33.3 & 1.98 & 6.68 & \\
\hline & 1.918 & 1.643 & 1.385 & 1.332 & & 1.425 & & 1.385 & & 38.8 & & & RITFOP $^{26}$ \\
\hline \multirow[t]{2}{*}{ Ge(TPP) } & 2.213 & - & 1.374 & 1.357 & - & 1.440 & - & 1.398 & - & 0.5 & 1.27 & 5.87 & \\
\hline & 2.194 & & 1.375 & 1.365 & & 1.433 & & 1.397 & & 0.0 & & & LIJVAC $^{4}$ \\
\hline \multirow[t]{2}{*}{$\mathrm{Ge}(\mathrm{TPP})(\mathrm{py})_{2}$} & 1.962 & 2.127 & 1.400 & 1.399 & 1.345 & 1.447 & 1.390 & 1.434 & 1.361 & 38.6 & 0.14 & 4.20 & \\
\hline & 1.937 & 2.105 & 1.400 & 1.387 & 1.360 & 1.433 & 2.812 & 1.424 & 1.387 & 49.2 & & & LIHYAD $^{4}$ \\
\hline $\operatorname{Ge}(\mathrm{TPP})(\text { thf })_{2}$ & 1.946 & 2.058 & 1.401 & 1.402 & 1.349 & 1.448 & 1.392 & 1.435 & 1.362 & 43.1 & 0.11 & 4.20 & \\
\hline $\mathrm{Ge}(\mathrm{TPP}) \mathrm{F}_{2}$ & 2.035 & 1.813 & 1.376 & 1.360 & - & 1.439 & - & 1.402 & - & 7.6 & 2.01 & 6.79 & \\
\hline $\mathrm{Ge}(\mathrm{TPP}) \mathrm{Cl}_{2}$ & 2.019 & 2.262 & 1.377 & 1.343 & & 1.435 & & 1.393 & & 0.4 & & & NIPKEC $^{27}$ \\
\hline $\mathrm{B}_{2}$ (Por) $^{\mathrm{b}}$ & 1.449 & & 1.415 & 1.401 & 1.347 & 1.442 & 1.385 & 1.417 & 1.351 & 0.0 & 0.24 & 5.14 & \\
\hline $\mathrm{B}_{2}(\mathrm{TPP})$ & 1.450 & - & 1.418 & 1.396 & 1.343 & 1.441 & 1.384 & 1.427 & 1.402 & 1.5 & 0.23 & 4.87 & \\
\hline$\left[\mathrm{B}_{2}(\mathrm{TPP})\right]^{2+}$ & 1.450 & - & 1.406 & 1.363 & - & 1.415 & - & 1.394 & - & 1.1 & 1.51 & - & \\
\hline $\mathrm{C}_{2}$ (Por) ${ }^{\mathrm{b}}$ & 1.427 & & 1.402 & 1.398 & 1.346 & 1.441 & 1.386 & 1.414 & 1.350 & 55.5 & 0.25 & 5.21 & \\
\hline \multirow{2}{*}{$\mathrm{C}_{2}(\mathrm{TPP})$} & 1.422 & - & 1.403 & 1.397 & 1.346 & 1.441 & 1.387 & 1.428 & 1.359 & 58.9 & 0.25 & 4.95 & \\
\hline & 1.446 & & 1.406 & 1.391 & 1.341 & 1.437 & 1.387 & 1.426 & 1.361 & 52.6 & & & SAKYIO $^{12}$ \\
\hline$\left[\mathrm{C}_{2}(\mathrm{TPP})\right]^{2+}$ & 1.423 & - & 1.395 & 1.369 & - & 1.414 & - & 1.396 & - & 58.9 & 0.73 & - & \\
\hline $\mathrm{P}(\mathrm{TPP})(\mathrm{Cl})(\mathrm{py})$ & 1.809 & $\begin{array}{l}2.078(\mathrm{py}) \\
2.136(\mathrm{Cl})\end{array}$ & 1.407 & 1.400 & 1.347 & 1.442 & 1.385 & 1.427 & 1.354 & 64.3 & 0.13 & 4.55 & \\
\hline $\mathrm{P}(\mathrm{TPP})(\mathrm{Ph})$ & 1.805 & 1.817 & 1.414 & 1.399 & 1.346 & 1.440 & 1.382 & 1.424 & 1.351 & 65.3 & 0.14 & 4.74 & \\
\hline $\mathrm{P}(\mathrm{TPP})(\mathrm{Ph})(\mathrm{py})$ & 1.823 & $\begin{array}{l}2.188(\mathrm{py}) \\
1.852(\mathrm{Ph})\end{array}$ & 2.810 & 1.401 & 1.347 & 1.443 & 1.386 & 1.429 & 1.356 & 63.5 & 0.14 & 4.44 & \\
\hline $\mathrm{As}(\mathrm{TPP})(\mathrm{Cl})(\mathrm{py})$ & 1.927 & $\begin{array}{l}2.197(\mathrm{py}) \\
2.236(\mathrm{Cl})\end{array}$ & 1.404 & 1.400 & 1.346 & 1.444 & 1.386 & 1.430 & 1.356 & 48.8 & 0.12 & 4.53 & \\
\hline As(TPP)(Ph)(py) & 1.943 & $\begin{array}{l}2.284(\mathrm{py}) \\
1.956(\mathrm{Ph}) \\
\end{array}$ & 1.401 & 1.400 & 1.347 & 1.445 & 1.388 & 1.434 & 1.359 & 47.7 & 0.14 & 4.40 & \\
\hline
\end{tabular}

${ }^{\mathrm{a}}$ Mean distances for longer and shorter bonds are indicated by subscripts 1 and $\mathrm{s}$, respectively.
${ }^{\mathrm{b}}$ Por $=$ porphine 


\section{References}

${ }^{1}$ Sanders, J. K. M.; Bampos, N.; Clyde-Watson, Z.; Darling, S. L.; Hawley, J. C.; Kim, H.-J.;

Mak, C. C.; Webb, S. J. Axial Coordination Chemistry of Metalloporphyrins. In The Porphyrin Handbook; Kadish, K.M.; Smith, K.M.; Guilard, R. Eds.; Academic Press: Cambridge, MA. 2000. Vol 3, Ch. 15, pp. 1-40.

${ }^{2}$ Brothers, P. J. Organoelement Chemistry of Main Group Porphyrin Complexes. Adv. Organomet. Chem. 2001, 48, 289-342.

${ }^{3}$ Cissell, J.A.; Vaid, T.P.; Rheingold, A. L. An Antiaromatic Porphyrin Complex:

Tetraphenylporphyrinato(silicon)(L) 2 (L = THF or Pyridine). J. Am. Chem. Soc. 2005, 127, 12212-12213.

${ }^{4}$ Cissell, J.A.; Vaid, T. P.; Yap, G. P. A. Reversible Oxidation State Change in Germanium(tetraphenylporphyrin) Induced by a Dative Ligand: Aromatic Ge ${ }^{\mathrm{II}}(\mathrm{TPP})$ and Antiaromatic $\mathrm{Ge}^{\mathrm{IV}}(\mathrm{TPP})$ (pyridine)2. J. Am. Chem. Soc. 2007, 129, 7841-7847.

${ }^{5}$ Cissell, J.A.; Vaid, T. P.; DiPasquale, A. G.; Rheingold, A. L. Germanium Phthalocyanine, $\mathrm{GePc}$, and the Reduced Complexes $\mathrm{SiPc}(\text { pyridine })_{2}$ and $\mathrm{GePc}$ (pyridine) ${ }_{2}$ Containing Antiaromatic $\pi$-Electron Circuits. Inorg. Chem. 2007, 46, 7713-7715.

${ }^{6}$ Song, H.-E.; Cissell, J. A.; Vaid, T. P.; Holten, D. Photophysics of Reduced Silicon Tetraphenylporphyrin. J. Phys. Chem. B 2007, 111, 2138-2142.

${ }^{7}$ Breslow, R. Antiaromaticity. Acc. Chem. Res. 1973, 6, 393-398.

${ }^{8}$ Although nearly all antiaromatic compounds exhibit a bond-alternating structure, magnetic antiaromaticity does not actually require such a structure. ${ }^{9}$

${ }^{9}$ For a symmetric, delocalized antiaromatic compound, see: Conradie, J.; Foroutan-Nejad, C.; Ghosh, A. Norcorrole as an Example of a Delocalized, Antiaromatic System. Sci. Rep. In press. https://doi.org/10.1038/s41598-019-39972-y.

${ }^{10}$ Weiss, A.; Pritzkow, H.; Brothers, P. J.; Siebert, W. Coordinated B 2 bridges in porphyrins unexpected formation of a diborane(4)- from a diborylporphyrin. Angew. Chem. Int. Ed. 2001, 40, 4182-4184. 
${ }^{11}$ Weiss, A.; Hodgson, M. C.; Boyd, P. D. W.; Siebert, W.; Brothers, P. J., Diboryl and diboranyl porphyrin complexes: synthesis, structural motifs, and redox chemistry: diborenyl porphyrin or diboranyl isophlorin? Chem. - Eur. J. 2007, 13, 5982-5993.

${ }^{12}$ Vaid, T. P. A Porphyrin with a C=C Unit at its Center. J. Am. Chem. Soc. 2011, 133, 1583815841.

${ }^{13}$ Sung, Y. M.; Vasiliu, M.; Dixon, D. A.; Bonizzoni, M.; Kim, D.; Vaid, T. P., Electronic structure and photophysics of $(\mathrm{C}=\mathrm{C})$ tetra-p-tolylporphyrin ${ }^{2+}$. Photochem. Photobiol. Sci. 2013, 12, 1774-1779.

${ }^{14}$ In reading this paper, the reader is urged to distinguish between the concepts of valence and oxidation state, which in fact are not synonymous. While in many cases valence and oxidation state are identical, in others such as $\mathrm{B}_{2}$ (Por) they differ. ${ }^{15,16}$

${ }^{15}$ Parkin, G. Valence, Oxidation Number, and Formal Charge: Three Related but Fundamentally Different Concepts. J. Chem. Educ. 2006, 83, 791-799.

${ }^{16}$ Ghosh, A.; Berg, S. Arrow Pushing in Inorganic Chemistry: A Logical Approach to the Chemistry of the Main-Group Elements. Wiley: New York; 2014, pp 1-311.

${ }^{17}$ Sayer, P.; Gouterman, M; Connell, C. R. Metalloid Porphyrins and Phthalocyanines. Acc. Chem. Res. 1982, 15, 73-79.

${ }^{18}$ Satoh, W.; Nadano, R.; Yamamoto, Y.; Akiba, K.-Y. First characterization of arsenic porphyrins: synthesis and $\mathrm{X}$-ray structure of $[(\mathrm{oep}) \mathrm{AsMe}(\mathrm{OH})]^{+} \mathrm{ClO}^{-}$. Chem. Commun. 1996, 2451-2452.

${ }^{19}$ Akiba, K.-Y.; Onzuka, Y.; Itagaki, M.; Hirota, H.; Yamamoto, Y. Synthesis of Antimony(V) Octaethylporphyrins That Contain a $\sigma$-Bonded Element-Carbon Bond. Organometallics 1994, 13, 2800-2803.

${ }^{20}$ Becke, A. D. Density-Functional Exchange-Energy Approximation with Correct Asymptotic Behavior. Phys. Rev. A 1988, 38, 3098-3100.

${ }^{21}$ Perdew, J. P. Density-functional approximation for the correlation energy of the inhomogeneous electron gas. Phys. Rev. 1986, B33, 8822-8824; Erratum: Phys. Rev. 1986, B34, 7406.

${ }^{22}$ Handy, N. C.; Cohen, A. Left-right correlation energy. J. Mol. Phys. 2001, 99, 403-412. 
${ }^{23}$ Lee, C.; Yang, W.; Parr, R. G. Development of the Colle-Salvetti Correlation-Energy Formula into a Functional of the Electron Density. Phys. Rev. B 1988, 37, 785-789.

${ }^{24}$ Stephens, J.; Devlin, F. J.; Chabalowski, C. F.; Frisch, M. J. Ab Initio Calculation of Vibrational Absorption and Circular Dichroism Spectra Using Density Functional Force Fields. J. Phys. Chem. 1994, 98, 11623-11627.

${ }^{25}$ Grimme, S.; Anthony, J.; Ehrlich, S.; Krieg, H. A Consistent and Accurate Ab Initio Parametrization of Density Functional Dispersion Correction (DFT-D) for the 94 Elements H-Pu. J. Chem. Phys. 2010, 132, 154104.

${ }^{26}$ Kane, K. M.; Lemke, F. R.; Petersen, J. L. trans-Difluorosilicon(IV) Complexes of Tetra-ptolylporphyrin and Tetrakis( $p$-(trifluoromethyl)phenyl)porphyrin: Crystal Structures and Unprecedented Reactivity in Hexacoordinate Difluorosilanes. Inorg. Chem. 1997, 36, 13541359.

${ }^{27}$ Lin, S.; Chen, Y.; Chen, J.; Liao, F.; Wang, S.; Wang, S. Crystal structures of chloro(mesotetraphenylporphyrinato)germanium(IV), $\mathrm{Ge}(\mathrm{tpp}) \mathrm{Cl}_{2}$, and dihydroxo(mesotetraphenylporphyrinato)germanium(IV), $\mathrm{Ge}(\mathrm{tpp})(\mathrm{OH})_{2}$, and two-stage hydrolysis of its homologue dimethoxo(meso-tetraphenylporphyrinato)germanium(IV), Ge(tpp)(OMe)2. Polyhedron 1997, 16, 2843-2850.

${ }^{28}$ The potential energy surfaces associated with ruffling are generally very soft and are exceptionally so for the antiaromatic isophlorin complexes. Readers wishing to reproduce the calculated geometries should use exceptionally fine integration grids and tight convergence criteria and subsequently determine the final geometries via a potential energy scan as a function of the ruffling dihedral.

${ }^{29}$ Vangberg, T.; Ghosh, A. A First-Principles Quantum Chemical Analysis of the Factors Controlling Ruffling Deformations of Porphyrins: Insights from the Molecular Structures and Potential Energy Surfaces of Silicon, Phosphorus, Germanium, and Arsenic Porphyrins and of a Peroxidase Compound I Model. J. Am. Chem. Soc. 1999, 121, 12154-12160.

${ }^{30}$ Ghosh, A.; Gonzalez, E.; Vangberg, T. Theoretical Studies of Low-Spin Six-Coordinate Iron(III) Porphyrins Relevant to Cytochromes $b$ : Variable Electronic Configurations, Ligand Noninnocence, and Macrocycle Ruffling. J. Phys. Chem. B 1999, 103, 1363-1367. 
${ }^{31}$ The very similar energies of the $C_{2 \mathrm{~h}}$ and $D_{2 \mathrm{~h}}$ geometries is thought to reflect a balance between the energy gain associated with desymmetrization of the $\pi$-system and the energy cost associated with distorting the $\sigma$ skeleton.

${ }^{32}$ Heilbronner, E. Why do some molecules have symmetry different from that expected? $J$. Chem. Educ. 1989, 66, 471-478.

${ }^{33}$ Shaik, S.; Shurki, A.; Danovich, D.; Hiberty P. C. A Different Story of $\pi$-Delocalization - The Distortivity of $\pi$-Electrons and Its Chemical Manifestations. Chem. Rev. 2001, 101, 1501-1539.

${ }^{34}$ Yip, K. L.; Duke, C. B.; Salaneck, W. R.; Plummer, E. W.; Lourbriel, G. Electronic structure of porphins: all valence electron molecular orbital theory and ultraviolet photoemission spectroscopy. Chem. Phys. Lett. 1977, 49, 530-535.

${ }^{35}$ Ghosh, A.; Almlöf, J. The ultraviolet photoelectron spectrum of free-base porphyrin revisited. The performance of local density functional theory. Chem. Phys. Lett. 1993, 213, 519-521. ${ }^{36}$ Ghosh, A. Substituent Effects on Valence Ionization Potentials of Free Base Porphyrins: A Local Density Functional Study. J. Am. Chem. Soc. 1995, 117, 4691-4699.

${ }^{37}$ Foroutan-Nejad, C.; Larsen, S.; Conradie, J.; Ghosh, A. Isocorroles as Homoaromatic NIRAbsorbing Chromophores: A First Quantum Chemical Study. Sci. Rep. 2018, 8, 11952.

${ }^{38}$ Foroutan-Nejad, C.; Ghosh, A. Magnetic Diversity in Heteroisocorroles: Aromatic Pathways in 10-Heteroatom-Substituted Isocorroles. ACS Omega 2018, 3, 15865-15869.

${ }^{39}$ Ghosh, A.; Larsen, S.; Conradie, J.; Foroutan-Nejad, C. Local versus global aromaticity in azuliporphyrin and benziporphyrin derivatives. Org. Biomol. Chem. 2018, 16, 7964-7970.

${ }^{40}$ Fliegl, H.; Sundholm, D. Aromatic Pathways of Porphins, Chlorins, and Bacteriochlorins. $J$. Org. Chem. 2012, 77, 3408-3414.

${ }^{41}$ Pathak, S.; Bast, R.; Ruud, K. Multiconfigurational Self-Consistent Field Calculations of the Magnetically Induced Current Density Using Gauge-Including Atomic Orbitals. J. Chem. Theory Comput. 2013, 9, 2189-2198. 
For Table of Contents only

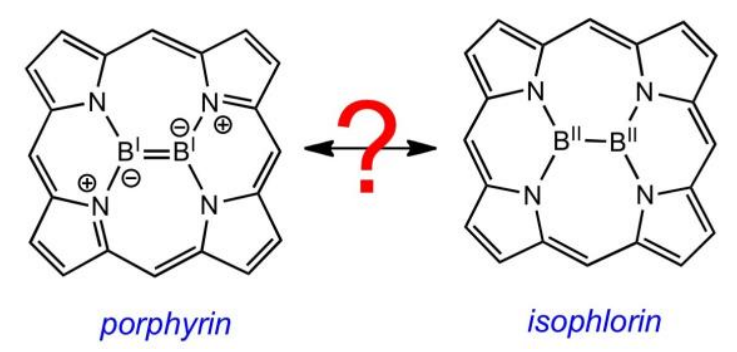

A comprehensive DFT reinvestigation of reduced main-group element porphyrins has addressed the issue of potential subvalent character for the main-group element centers. 